\title{
Direitos Humanos EM DEBATE: A EXPERIÊNCIA DO CURSO DE extensão "Democracia, Cidadania e Acesso à Justiça no Brasil"
}

\section{Human Rights in discussion: the extension course's "Democracy, Citizenship and Access to Justice in Brazil" experience}

\author{
Felipe Dutra Asensi* \\ Baltazar José Vasconcelos Rodrigues*
}

\begin{abstract}
RESUMO
O presente texto tem por objetivo relatar a experiência do curso de extensão "Democracia, Cidadania e Acesso à Justiça no Brasil", que ocorreu em junho do ano de 2006 na Faculdade de Direito da UFF e nasceu do projeto de monitoria de Sociologia Jurídica e Teoria Geral do Processo. Este curso foi ministrado pelos respectivos monitores, sob a coordenação dos orientadores, e recebeu o apoio institucional da Faculdade de Direito (respaldo administrativo) e do Centro Acadêmico Evaristo da Veiga (respaldo estudantil). Ao final, foi realizada uma avaliação do curso por intermédio de um questionário auto-aplicável, o qual indicou que o curso recebeu ampla receptividade e constitui-se como uma forma inovadora de articulação entre extensão e monitoria.
\end{abstract}

Palavras-chave: Direitos humanos; ensino jurídico; cidadania.

\begin{abstract}
The present text has the objective to show the experience of the short course "Democracy, Citizenship and Access to Justice in Brazil", which occurred in June 2006 in the Fluminense Federal University's Law School and was born from the Juridical Sociology's and General Theory of the Process' assistance project. This course was taught by the assistants of each subject and coordinated by the teachers. It received the institutional support from the Law School (administrative endorsement) and from the Academic Center Evaristo da Veiga (students endorsement). In the end, there was an evaluation of the course through a questionnaire, which indicated that the course had received a great concern and consists as a new jointaction strategy between extension and assistance.
\end{abstract}

Keywords: Human rights; legal education; citizenship.

\section{RESUMEN}

El texto tiene por objetivo demonstrar la experiencia vivida con la realización del curso "Democracía, Ciudadanía y Acesso a la Justicia en Brasil", que ocurrió en junio del año de 2006 en la Faculdad de Derecho de la Universidade Federal Fluminense (Niterói, Brasil). Nació de un proyecto de monitoría de las disciplinas Sociología Jurídica y Teoría General del Proceso. Este curso fue conducido por los respectivos monitores, bajo la orientación de los profesores y recibió soporte institucional de la Faculdad de Derecho (soporte administrativo) y del Centro Académico Evaristo da Veiga (soporte estudiantil). En su término, se

\footnotetext{
Bacharel em Ciências Sociais pela UERJ. Bacharel em Direito pela UFF. Mestrando em Sociologia pelo IUPERJ. Bolsista do CNPq. Endereço: Rua Assis Moura, 54 - Jacarepaguá - Rio de Janeiro - RJ - Cep.: 22770-280. Telefone: (21) 33423145 / 86899998. E-mail: felipedml@yahoo.com.br.

** Bacharel em Direito pela UFF.
} 
realizó una evaluación, por medio de preguntas a los participantes, por los cuales se indicó que el Curso recibió larga receptividad y fue una forma nueva de articulación entre actividades de monitoría y actividades de extensión de la enseñanza.

Palabras-clave: Derechos humanos; ensino jurídico; ciudadanía.

\section{Apresentação: o percurso institucional}

O curso de extensão "Democracia, Cidadania e Acesso à Justiça no Brasil", realizado no ano de 2006, foi fruto da iniciativa dos monitores das disciplinas de Sociologia Jurídica e Teoria Geral do Processo - Felipe Dutra Asensi e Baltazar José Vasconcelos Rodrigues - e contou com a orientação dos próprios professores das respectivas disciplinas: Roberto Fragale Filho e Delton Ricardo Soares Meirelles. Basicamente, o curso teve como escopo articular os temas democracia, cidadania e acesso à justiça, sob o prisma dos direitos humanos, de modo a conjugar os programas de monitoria às atividades de extensão.

O primeiro passo para a concretização do curso consistiu na apresentação da proposta e do projeto aos respectivos professores das disciplinas, que o aprovaram, de imediato. Em seguida, os esforços se concentraram na busca do respaldo institucional junto à Faculdade de Direito da Universidade Federal Fluminense - local onde seria realizado o curso - $e$ ao Centro Acadêmico Evaristo da Veiga, que também o aprovaram.

Com ambos os apoios, realizamos a divulgação do evento por meio de cartazes que foram fixados em toda a Faculdade de Direito. Em virtude do curto tempo de divulgação (cerca de cinco dias), imaginávamos que não iríamos obter um quorum desejável; porém, para nossa surpresa, cerca de cinqüenta pessoas estiveram presentes no primeiro dia, o que denota a relevância do tema em questão para a formação do jurista.

O curso ocorreu às segundas e sextasfeiras do mês de junho, cuja carga horária total de vinte horas foi distribuída em sete encontros. $\mathrm{O}$ certificado de participação foi conferido aos alunos que compareceram a, pelo menos, cinco encontros.

No primeiro dia, realizamos uma breve apresentação do curso, seus objetivos, metas, regras de presença, certificado, etc. Na abertura, contamos com a presença de representantes do Centro Acadêmico e da Faculdade de Direito, que realizaram um breve discurso de boasvindas. Em seguida, foi aberta a palavra para que cada uma das pessoas presentes pudesse se apresentar e dizer o motivo pelo qual estava participando do curso.

De uma forma geral, as pessoas manifestaram seu interesse pelo caráter inovador do evento, sendo certo que seu objetivo consistia em promover uma reflexão crítica da democracia no Brasil sob o prisma da cidadania e do acesso à justiça. Essa primeira impressão que as pessoas evidenciaram nos permitiu concluir que a escolha do tema dos direitos humanos foi acertada, na medida em que tínhamos uma demanda crescente na Faculdade de Direito para a discussão destes assuntos.

Nas aulas seguintes, tivemos por objetivo fazer com que os alunos também participassem. Por essa razão, a participação foi estimulada ao máximo, pois partimos do pressuposto de que um curso de extensão deve ser caracterizado pela construção coletiva de idéias e, para isso, devíamos diluir a barreira existente entre instrutor e aluno, enfatizando a troca mútua de conhecimentos.

O resultado foi uma avaliação que os participantes realizaram no último encontro, com ela revelando a boa receptividade que o curso obteve e o sucesso da metodologia de ensino utilizada. 
Objetivos e metas do curso de extensão

O curso "Democracia, Cidadania e Acesso à Justiça no Brasil” teve como objetivo satisfazer uma demanda cada vez mais crescente no campo do direito, a qual preconiza que as reflexões sobre os direitos humanos no Brasil devam ser cada vez mais críticas e multidisciplinares. Neste sentido, partiu-se do pressuposto de que o tema "Democracia, cidadania e acesso à justiça no Brasil" é híbrido, na medida em que seu conteúdo não faz parte nem do campo específico das ciências sociais e nem do direito.

Basicamente, a prioridade foi a multidisciplinaridade, procurando propiciar uma reflexão crítica ao interlocutor e estimulando a sua capacidade analítica por intermédio de temas que não são exclusivos de somente um campo de saber (Desafios da democracia; Acesso à justiça; Cidadania; etc.). A reflexão sobre democracia, cidadania e acesso à justiça no Brasil situa-se cada vez mais como condição fundamental para exames públicos. Além disso, esta forma de pensar os fenômenos tem servido como ferramenta de aperfeiçoamento da atuação de movimentos sociais, já que sua estratégia privilegiada tem incidido justamente na reivindicação de direitos por intermédio do exercício de sua cidadania. Por isso, tais movimentos têm enfatizado o ensino e a informação como forma de otimização das reivindicações.

Em decorrência disto, o curso se caracterizou pela heterogeneidade e é nela mesmo que residiu o seu sucesso. A partir do diálogo entre concepções e objetivos distintos, pôde-se efetivamente obter um produto de qualidade, inovador e muito positivo para os alunos, ministrantes e a própria Faculdade de Direito.

Basicamente, o curso teve como fio condutor a formação política brasileira $e$ suas conseqüências no campo da cultura e da cidadania. Portanto, não se tratou de promover uma linearidade histórica acerca dos fenômenos sociais, mas sim de pontuar algumas questões que propiciassem aos interlocutores uma atitude de estranhamento, crítica e rigor em sua análise.

Foram tratados temas diversos a partir de textos, tais como desigualdade social, finalidades do Estado, democracia, acesso à justiça, etc. A heterogeneidade de temas se diluiu quando, sob a perspectiva crítica, analisamos em que medida estas questões contribuíram para a constituição da cidadania e da cultura brasileira.

\section{O plano do curso e seu programa}

O curso foi dividido em três blocos, aos quais corresponderam duas aulas cada um. O primeiro bloco visou promover uma reflexão sobre a democracia no Brasil, tomando como referencial o processo de formação dessa democracia e os desafios atuais para a sua efetivação. O segundo bloco, por sua vez, visou promover uma reflexão sobre a cidadania no Brasil, tomando como referencial o processo de conquista de direitos sociais e a constituição da cidadania em nosso país. Por fim, o terceiro bloco visou promover uma reflexão sobre o acesso à justiça no Brasil, tomando como referencial os traços de constituição de nossa cidadania e a formação da democracia brasileira.

Não se tratou de discutir amplamente todos os aspectos atinentes aos três blocos, mas sim de oferecer subsídios que sirvam de instrumento para uma abordagem crítica acerca dos fenômenos jurídicos e as suas implicações no tema dos direitos humanos. Deste modo, a cada aula correspondeu um texto científico - exposto pelos ministrantes de forma alternada -, de modo que cada ministrante proferiu três aulas ao longo do curso.

Após a exposição, a turma era organizada em grupos de cinco pessoas (nunca coin- 
cidentes), os quais discutiam um segundo texto, de caráter auxiliar e enxuto, sob o prisma da aula dada pelo ministrante. Em seguida, o grupo apresentava o que discutiu para o resto da turma, promovendo o debate e desenvolvendo o raciocínio crítico-analítico.

\section{Avaliação dos participantes}

No último dia do curso foi entregue a cada participante presente um questionário de avaliação, que foi respondido e devolvido na mesma ocasião (vinte e seis questionários respondidos no total). O questionário, de caráter anônimo e auto-aplicável, se dividiu em dois grandes grupos: no primeiro, procurou-se averiguar a satisfação dos participantes com relação ao curso; ao passo que, no segundo, procurou-se averiguar a satisfação dos participantes com relação aos ministrantes.

Esta avaliação foi feita considerando números de um a quatro, sendo que o número um corresponde ao mínimo e o número quatro ao máximo. Segue, na tabela 1, o resultado.

Deste modo, a avaliação indica que o curso efetivamente contribuiu para a formação dos participantes, seja através do estímulo ao pensamento crítico, seja através do estímulo ao debate e à troca de conhecimentos. A avaliação dos ministrantes, por sua vez, indica que a metodologia de ensino obteve sucesso, na medida em que a organização das aulas e a participação dos alunos possibilitaram a consecução dos objetivos.

TABELA 1 - AVALIAÇÃO DOS PARTICIPANTES

\begin{tabular}{|c|c|c|c|c|c|c|}
\hline \multicolumn{2}{|c|}{ Em relação ao curso } & \multirow{2}{*}{$\frac{\mathbf{1}}{0 \%}$} & \multirow{2}{*}{$\frac{2}{14 \%}$} & \multirow{2}{*}{$\begin{array}{c}\mathbf{3} \\
57 \%\end{array}$} & \multirow{2}{*}{$\begin{array}{c}4 \\
29 \%\end{array}$} & \multirow[b]{2}{*}{ Profunda } \\
\hline Abordagem do tema & Superficial & & & & & \\
\hline $\begin{array}{c}\text { Qualidade da } \\
\text { bibliografia sugerida }\end{array}$ & Insuficiente & $0 \%$ & $0 \%$ & $20 \%$ & $80 \%$ & Suficiente \\
\hline Qualidade dos textos auxiliares & Insuficiente & $0 \%$ & $15 \%$ & $42 \%$ & $42 \%$ & Suficiente \\
\hline $\begin{array}{l}\text { Surpreendeu suas } \\
\text { expectativas iniciais? }\end{array}$ & Não & $4 \%$ & $7 \%$ & $18 \%$ & $71 \%$ & $\operatorname{Sim}$ \\
\hline $\begin{array}{l}\text { Contribuição para a } \\
\text { sua formação geral }\end{array}$ & Inexistente & $0 \%$ & $11 \%$ & $19 \%$ & $70 \%$ & Significativa \\
\hline $\begin{array}{l}\text { Contribuição para o } \\
\text { desenvolvimento de } \\
\text { sua capacidade crítica }\end{array}$ & Inexistente & $0 \%$ & $8 \%$ & $31 \%$ & $62 \%$ & Significativa \\
\hline $\begin{array}{l}\text { Os seus conhecimentos } \\
\text { anteriores foram suficientes } \\
\text { para acompanhar a disciplina? }\end{array}$ & Não & $4 \%$ & $18 \%$ & $21 \%$ & $57 \%$ & $\operatorname{Sim}$ \\
\hline Avaliação geral do curso & Ruim & $0 \%$ & $0 \%$ & $43 \%$ & $57 \%$ & Ótimo \\
\hline \multicolumn{2}{|c|}{ Em relação aos ministrantes } & 1 & 2 & 3 & 4 & \\
\hline Forma de exposição das idéias & Ininteligível & $0 \%$ & $2 \%$ & $20 \%$ & $79 \%$ & Clara \\
\hline $\begin{array}{l}\text { Coerência no desenvolvimento } \\
\text { do conteúdo }\end{array}$ & Incoerente & $0 \%$ & $4 \%$ & $14 \%$ & $82 \%$ & Coerente \\
\hline $\begin{array}{l}\text { Incentivo à participação } \\
\text { dos alunos }\end{array}$ & Pouco & $0 \%$ & $7 \%$ & $20 \%$ & $73 \%$ & Muito \\
\hline Utilização de exemplos & Ininteligível & $0 \%$ & $2 \%$ & $45 \%$ & $54 \%$ & Clara \\
\hline Avaliação geral & Ruim & $0 \%$ & $2 \%$ & $30 \%$ & $68 \%$ & Ótimo \\
\hline
\end{tabular}


Interpretando a evolução da presença

A expressão quantitativa da presença dos alunos ao longo do curso é uma importante ferramenta para analisarmos a questão de sua oscilação. Não se trata, aqui, de promover uma análise estatística aprofundada das diferentes variáveis presentes no abandono do curso, mas tão somente mapear o desenvolvimento e indicar possíveis interpretações que sirvam de matriz para outras inferências.

De início, devemos considerar a evolução da presença ao longo dos encontros e destacar quais foram os pontos problemáticos e suas possíveis deficiências. Observe o gráfico abaixo.

No primeiro encontro, contamos com a presença de quarenta e três pessoas. Este número decresceu conforme se passaram os encontros, estabilizando-se na faixa de vinte e cinco pessoas. Entretanto, esta análise por si só não nos oferece elementos para pensarmos os determinantes da presença, o que demanda uma outra forma de análise: a correlação entre o número de pessoas e o número de dias em que cada pessoa compareceu. Observe a tabela 2.

Nota-se que temos dois cumes na tabela: um, menor, que representa o número de pessoas que só vieram num dia de curso; outro, maior, que representa o número de pessoas que vieram em cinco dias de curso. Este segundo cume pode ser facilmente explicado, na medida em que o requisito mínimo para obter o certificado foi a presença em cinco dias, não importando se a pessoa se ausentasse nos dois restantes. Analisemos, portanto, a associação entre o grande número de pessoas do primeiro dia e o progressivo decréscimo das presenças ao longo do curso por meio do gráfico da página seguinte.

\section{GRÁFICO 1 - EVOLUÇÃO DA PRESENÇA POR ENCONTRO}

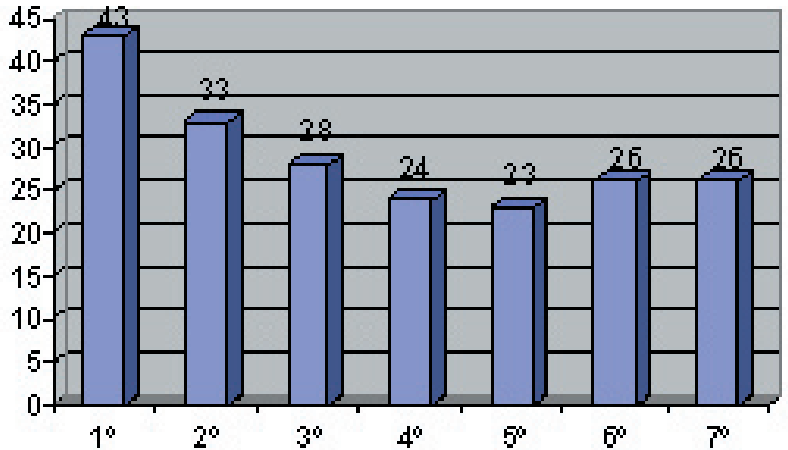

TABELA 2 - CORRELAÇÃO ENTRE PESSOAS E DIAS DE COMPARECIMENTO

\begin{tabular}{ccc}
\hline Pessoas que compareceram & Número de pessoas & $\mathbf{\%}$ \\
\hline Um dia & 15 & 27,7 \\
Dois dias & 5 & 9,2 \\
Três dias & 1 & 1,8 \\
Quatro dias & 0 & 0 \\
Cinco dias & 25 & 46,2 \\
Seis dias & 6 & 11,1 \\
Sete dias & 2 & 3,7 \\
\hline Total & $\mathbf{5 4}$ & $\mathbf{1 0 0}$ \\
\hline
\end{tabular}


GRÁFICO 2 - CORRELAÇÃO ENTRE PESSOAS E DIAS

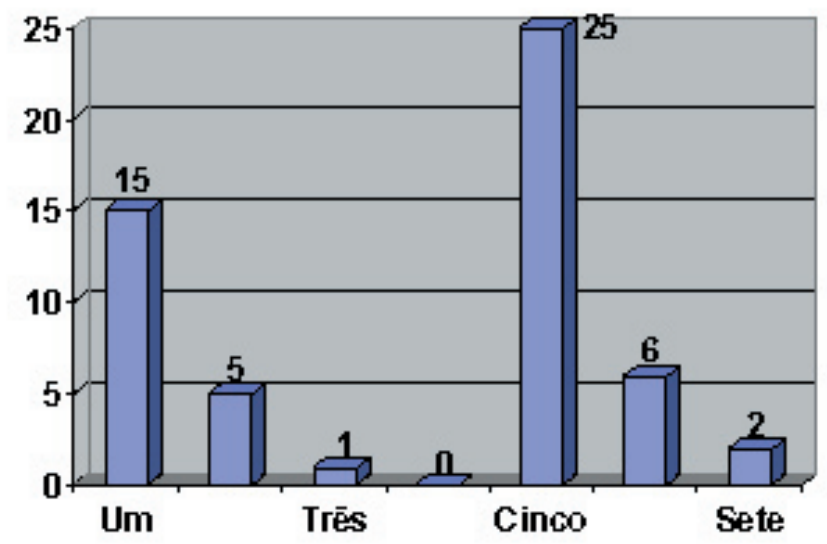

De fato, observamos a concentração das presenças nos dois pólos anteriormente citados. Temos um número razoável de pessoas que só assistiram a um dia de curso, e um número maior de pessoas que assistiram a, pelo menos, cinco dias.

Tomando como referência a lista de presença, pudemos delimitar em qual fase do curso as pessoas exerciam suas faltas. Mais precisamente, observamos que das quinze pessoas que só assistiram a um dia, doze só assistiram ao primeiro dia - que correspondeu à apresentação do curso - e o restante assistiu ao segundo. Desta forma, não tivemos pessoas que só assistiram uma vez ao curso a partir do terceiro encontro, o que demonstra que o abandono se deu, em sua maior parte, antes das aulas dos ministrantes efetivamente terem início.

Por essa razão, cumpre-nos refletir $e$ indicar determinados aspectos que sirvam de interpretação para essa concentração de abandonos no início do curso. Dentre as possíveis causas, apontamos: a) descompasso entre a expectativa pessoal do curso e o que foi apresentado no primeiro dia; b) circunstâncias eventuais (ex.: alunos que iniciaram estágios forenses; alunos cujo horário da tarde foi ocupado por atividades esportivas; simultaneidade da copa do mundo de futebol; etc.); c) desistência pura e simples; d) má apresentação.

Logicamente, as causas podem extrapolar as enumeradas. Porém, deve-se admitir que a associação entre o abandono do curso e a sua qualidade só poderia ser feita se houvesse um abandono progressivo ao longo do mesmo, o que não ocorreu. A partir dos gráficos e tabelas, observamos que a evasão se deu fortemente no primeiro dia - o dia da apresentação - que, obviamente, não reflete nem substitui as aulas realizadas posteriormente. Se o abandono fosse nas aulas seguintes, poderíamos pensar que estivesse relacionado à qualidade das aulas, material bibliográfico ou metodologia de ensino; porém, ao concentrarse majoritariamente no primeiro dia, resta-nos concluir que não foi em virtude da substância do curso que se deu o abandono.

\section{Considerações finais}

De uma forma geral, pode-se dizer que os objetivos propostos pelo curso foram satisfeitos. Ao final, pôde-se observar que os alunos valorizaram o lado crítico-analítico, enfatizando que os fenômenos jurídicos não devem ser pensados de forma descolada dos fenômenos sociais. Nesta linha, compreendemos que os conhecimentos adquiridos ao longo do curso serviram a um propósito mais amplo, que consiste na conscientização dos estudantes do seu papel de formadores de opinião. O ambiente 
criado propiciou que futuros operadores do direito vissem, por formas alternativas à tradicional sala de aula, uma nova forma de pensar o direito por meio da ênfase na construção coletiva de conhecimento e da defesa do papel do jurista para a consolidação da democracia, cidadania e acesso à justiça.

De uma forma específica, a avaliação nos mostra que o curso teve uma ampla receptividade por parte dos alunos, na medida em que boa parte dos quesitos recebeu conceito máximo. Com relação ao curso, o sucesso da avaliação pode ser atribuído a uma conjunção de fatores, dentre os quais destacamos a qualidade da bibliografia e a forma de organização das aulas, que se subdividiram entre exposição $e$

\section{REFERÊNCIAS}

\section{Bloco "Democracia"}

BONAVIDES, Paulo. Do Estado liberal ao Estado social. Rio de Janeiro: Forense, 1980.

CITTADINO, Gisele. Judicialização da política, constitucionalismo democrático e separação de poderes. In: VIANNA, Luiz Werneck (Org.). Democracia e os três poderes no Brasil. Belo Horizonte: Editora UFMG, 2003.

\section{Bloco "Cidadania"}

EHRLICH, Eugen. O estudo do direito vivo. In: SOUTO, Cláudio; FALCÃO, Joaquim (Orgs.). Sociologia e Direito: textos básicos para a disciplina sociologia jurídica. São Paulo: Pioneira, 1999. debate. Com relação aos ministrantes, houve boa receptividade dos participantes na exposição dos temas e no desempenho didático.

Deste modo, é possível afirmar que o curso correspondeu ou surpreendeu as expectativas. $\mathrm{O}$ curso iniciou com a presença de cinqüenta e quatro participantes, dos quais trinta e três (cerca de 61\%) tiveram direito a certificado. Ficou notável, portanto, a satisfação do público com o desenvolvimento do projeto. Não obstante, o curso abriu portas para novas iniciativas de outros monitores e ampliou o espaço de debate e de troca de conhecimento na própria universidade, servindo como ponte de reflexão entre os direitos assegurados $e$ as práticas concretas dos atores em seu cotidiano.

NETTO, Menelick de Carvalho. Controle de constitucionalidade e democracia. In: MAUÉS, Antônio G. Moreira. Constituição e democracia. São Paulo: Max Limonad, 2001.

\section{Bloco "Acesso à justiça"}

CAPPELLETTI, Mauro. Problemas de reforma do processo civil nas sociedades contemporâneas. In: MARINONI, Luiz Guilherme (Org.). O processo civil contemporâneo. Curitiba: Juruá, 1994.

; GARTH, Bryan. Acesso à Justiça. Porto Alegre: Sergio Antonio Fabris, 1999.

Texto recebido em 15 fev. 2008 Texto aprovado em 04 abr. 2008 